\title{
A Grand History of Interpreting Paleontological Resources at Grand Canyon National Park
}

Diana Boudreau, Ronnie Colvin, Earle Spamer
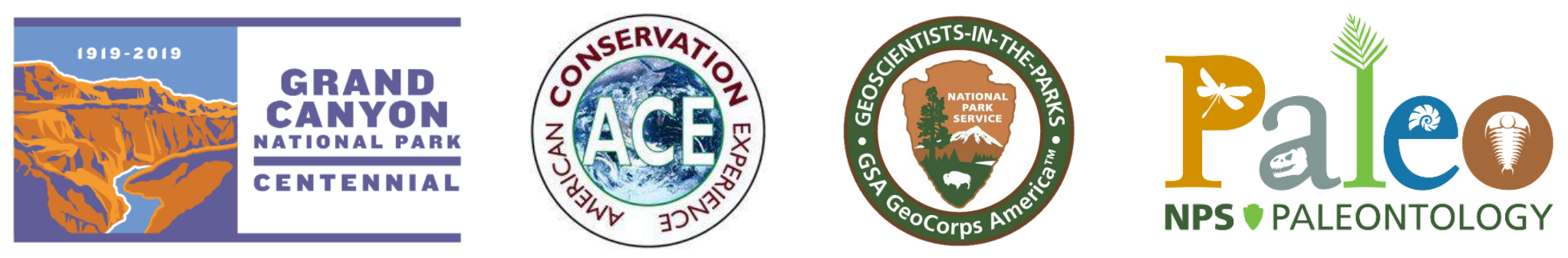


\section{Paleontological Resources}

- $32 \%$ of Earth's geologic history exposed

- 1 billion years of fossil life

- Fundamental resource
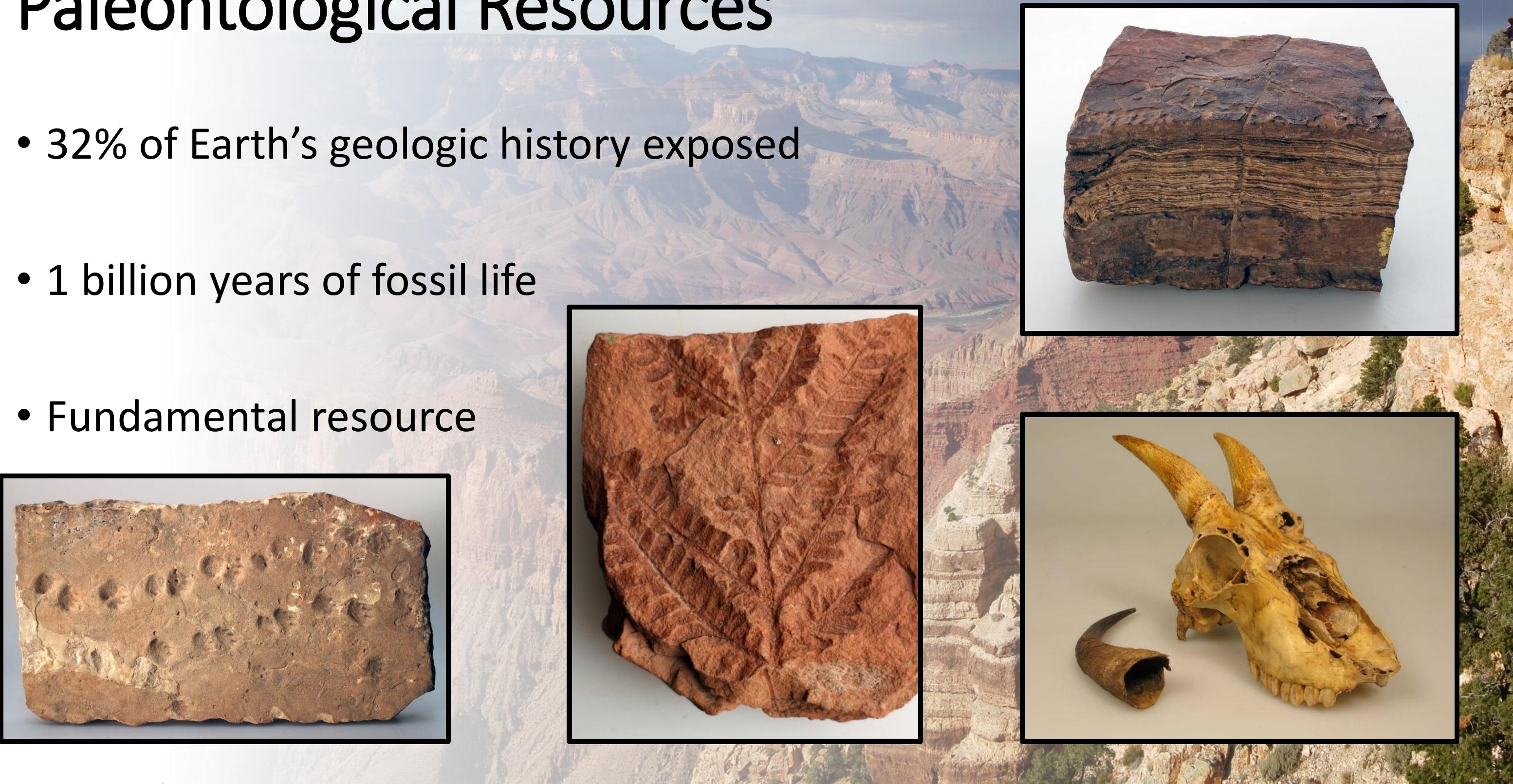


\section{John Strong Newberry}

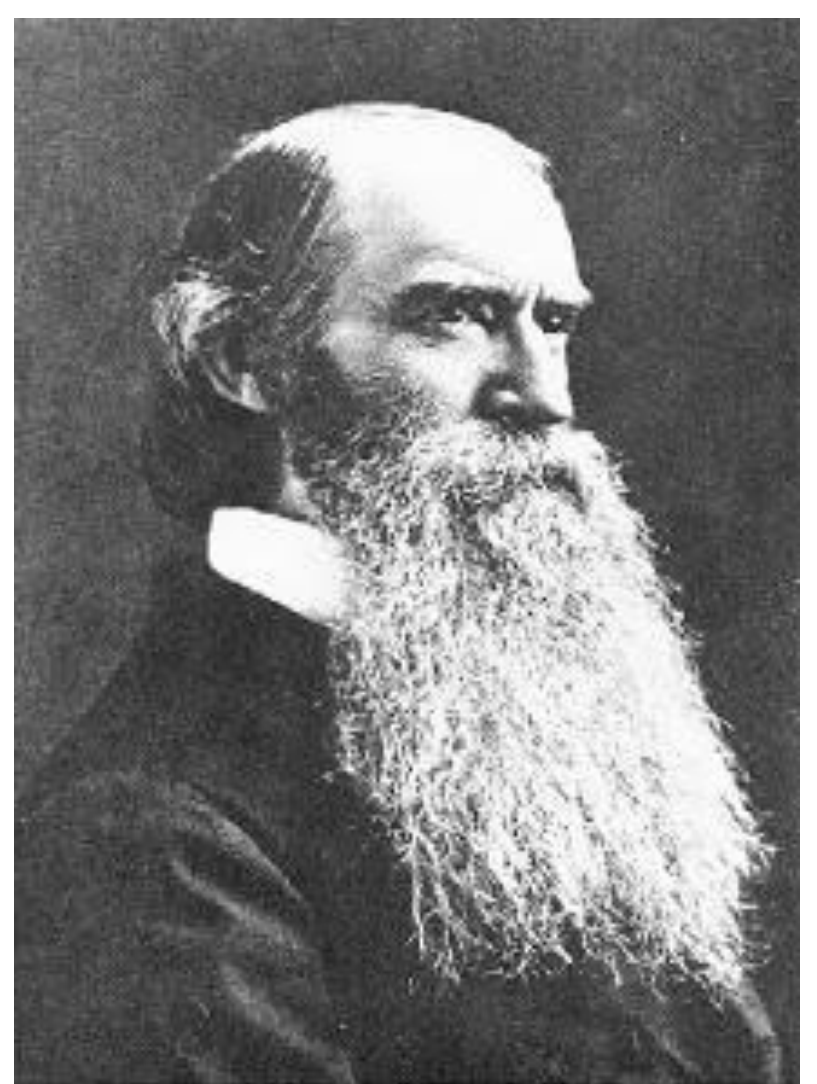

Dr. Joln Strong Newberny 1822-1892

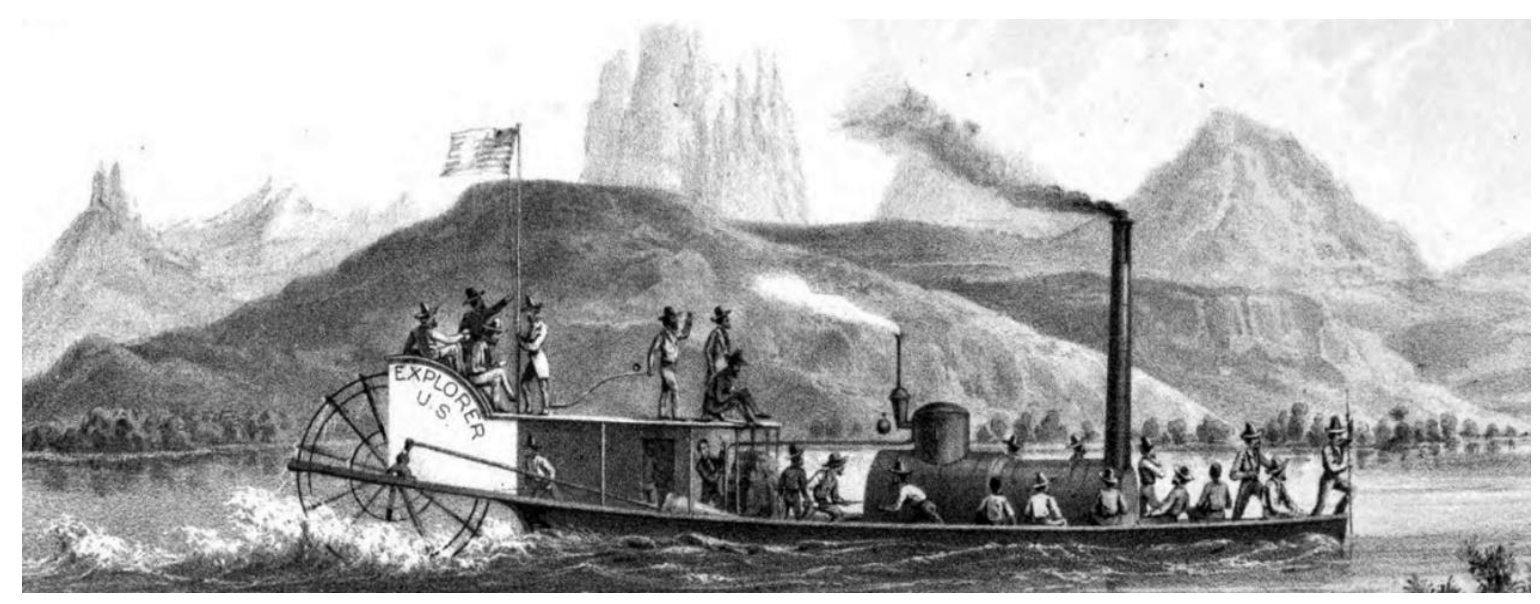

"In the absence of [suitable] fossils it is impossible to determine the precise geological age of any of the strata composing the ... section below the limestone which forms the summit of the cliffs." - J. Newberry, 1857

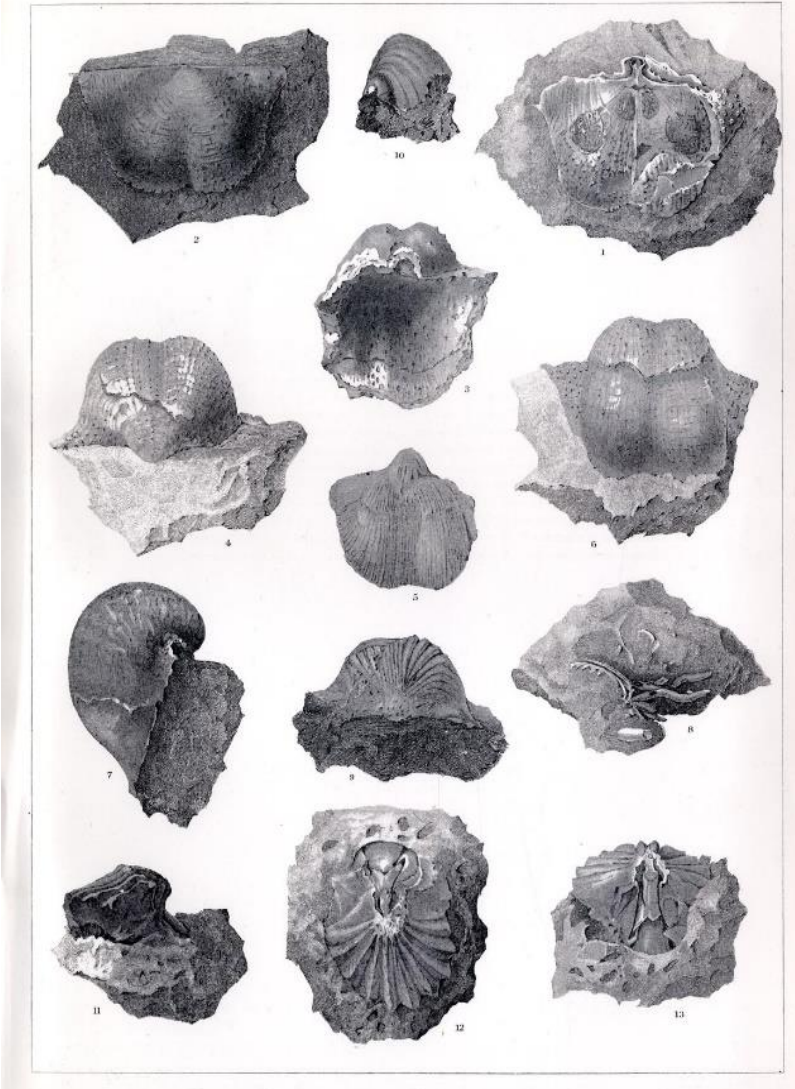

Newberry, 1861, Plate 2 
Grand Canyon National Park's purpose is to preserve and protect Grand Canyon's unique geologic, paleontologic, and other natural and cultural features for the benefit and enjoyment of the visiting public. 
Grand Canyon National Park's purpose is to preserve and protect Grand Canyon's unique geologic, paleontologic, and other natural and cultural features for the benefit and enjoyment of the visiting public. 
Grand Canyon National Park's purpose is to preserve and protect Grand Canyon's unique geologic, paleontologic, and other natural and cultural features for the benefit and enjoyment of the visiting public. 


\section{Charles Gilmore (1902-1928)}
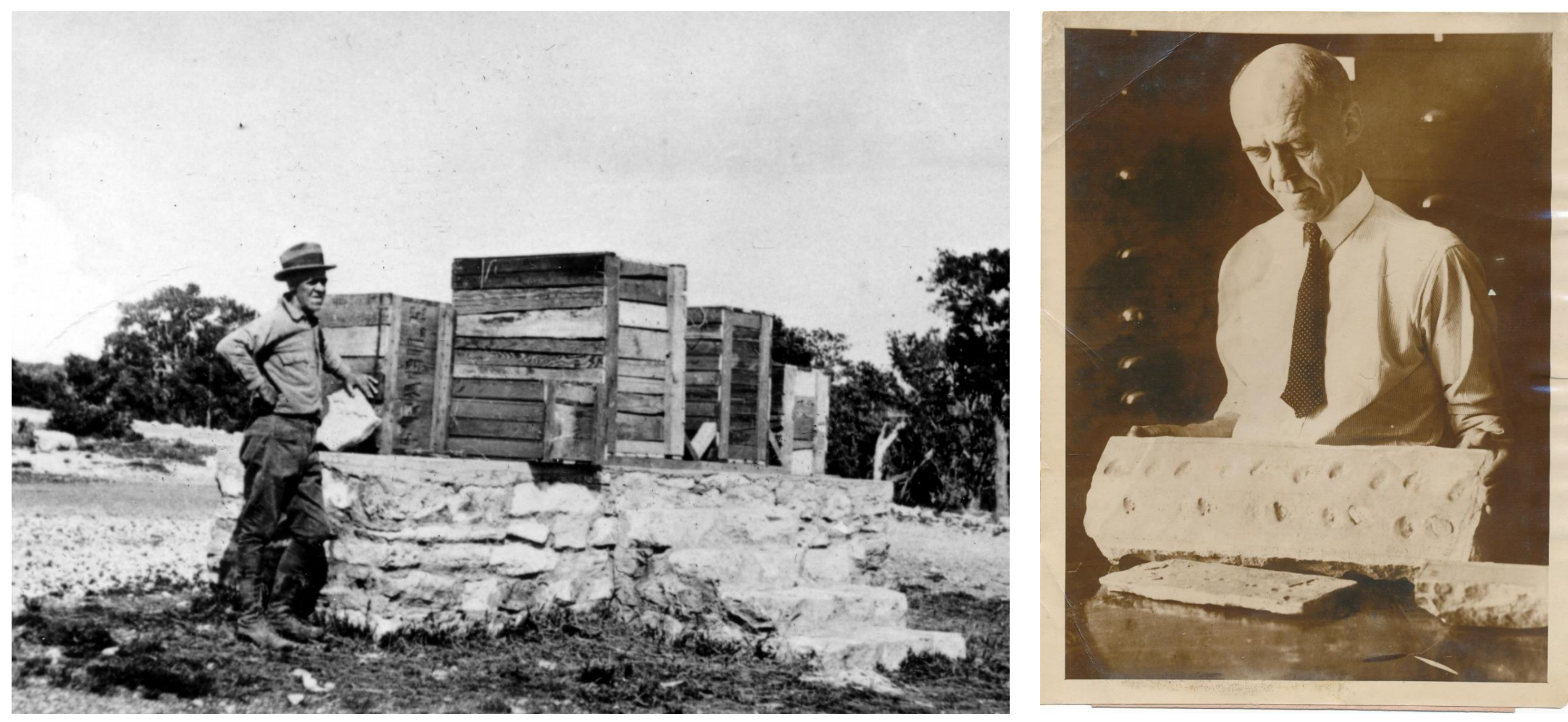


\section{Hermit Tracksite Exhibit (1924)}
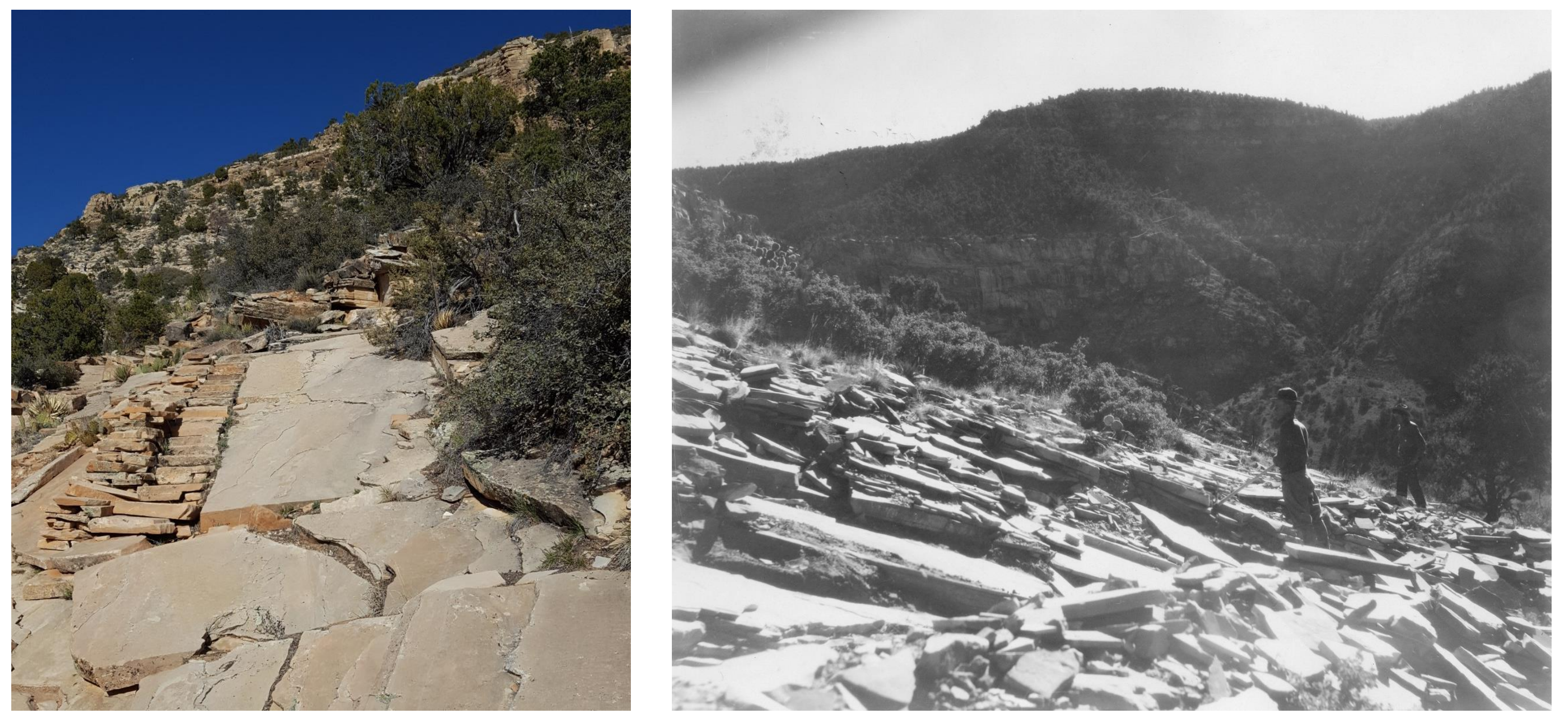


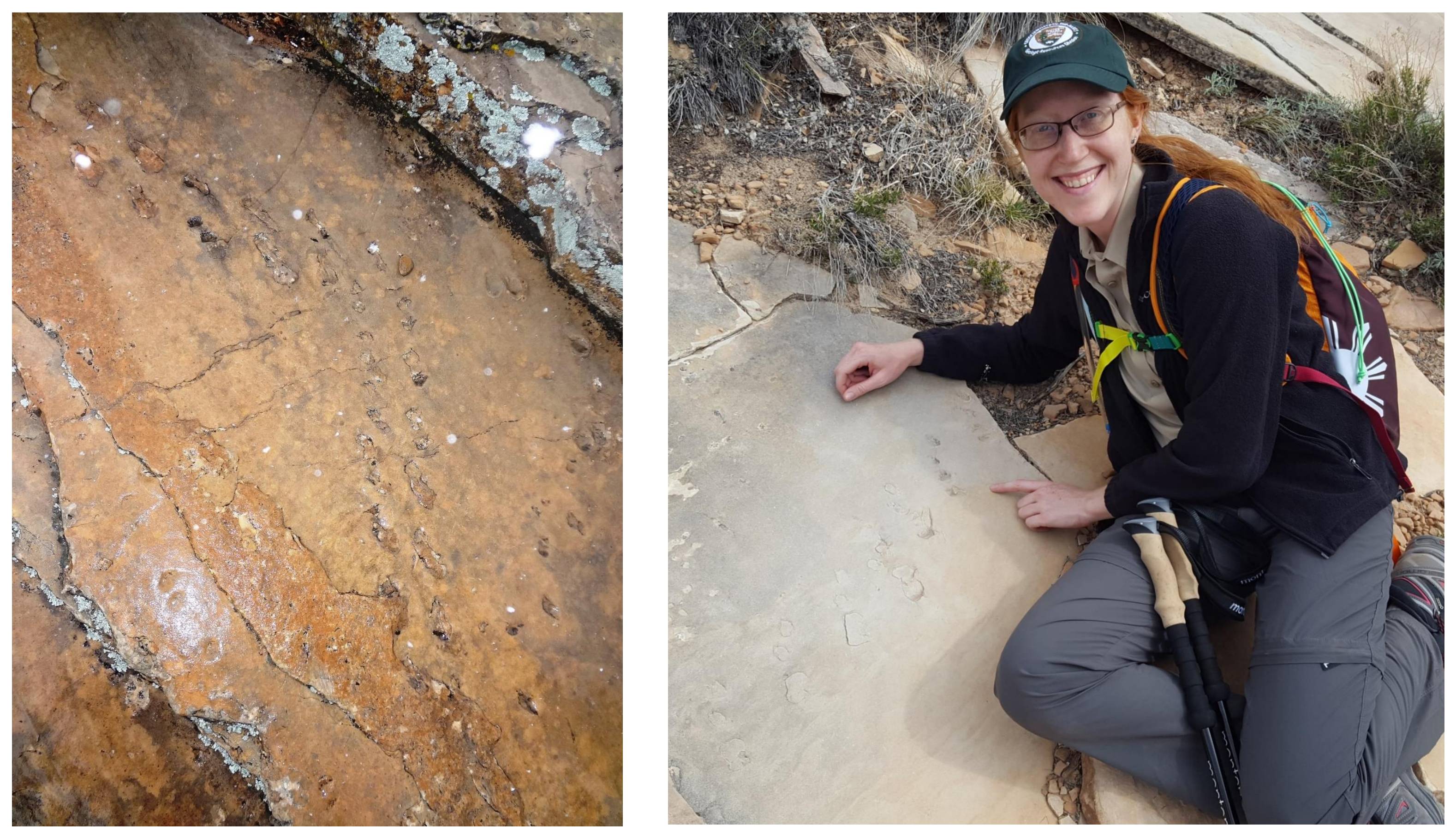




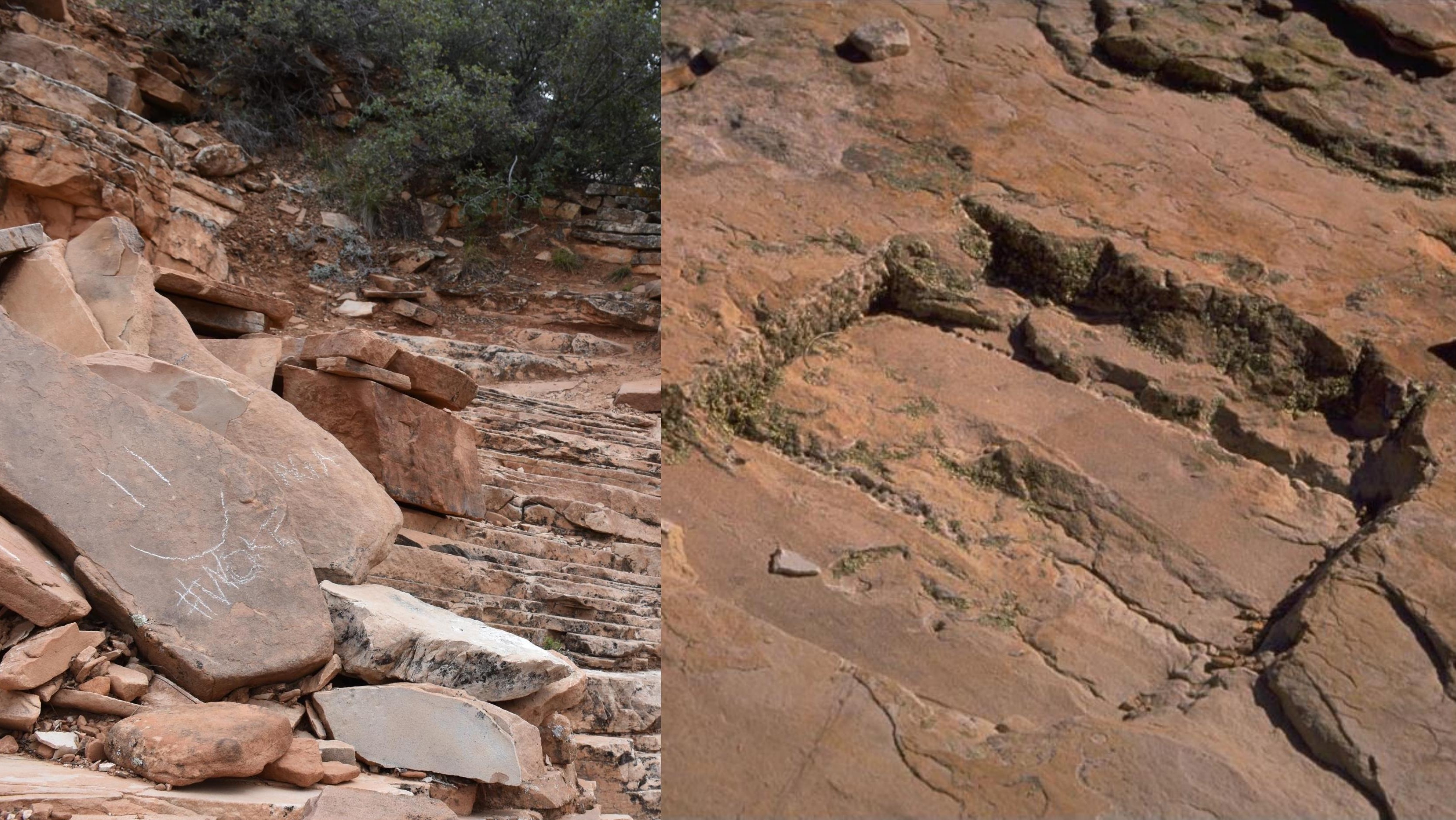




\section{Fossil Fern Exhibit (1937)}
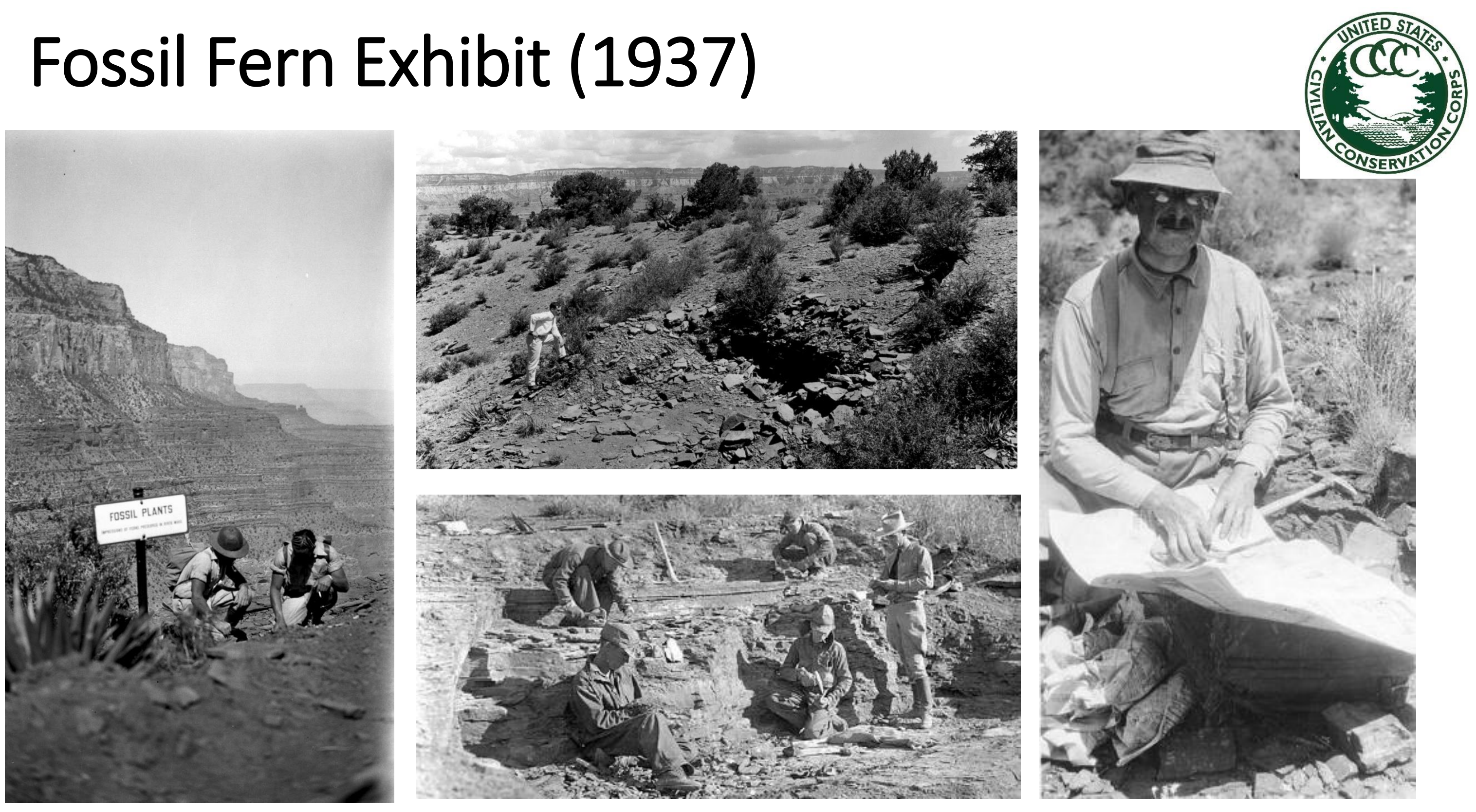


\section{Fossil Fern Exhibit}
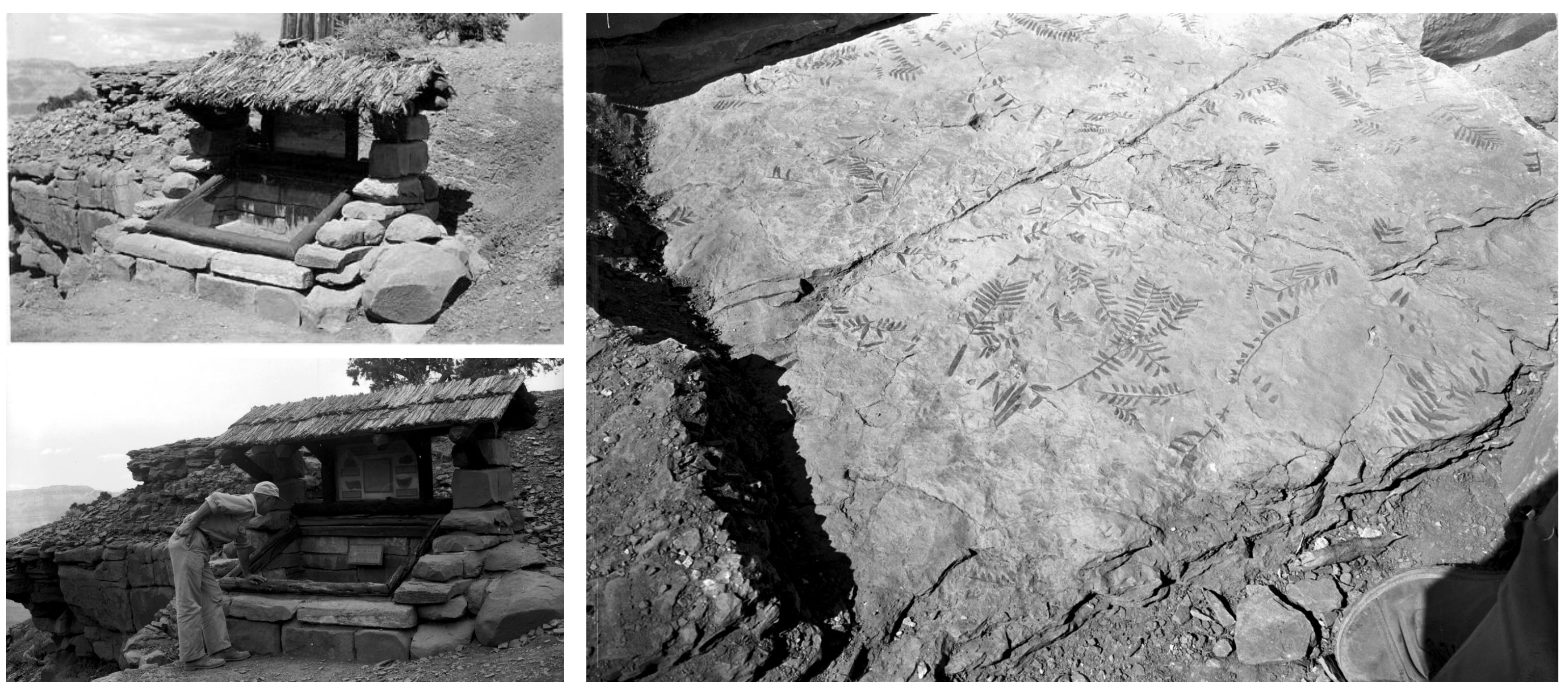


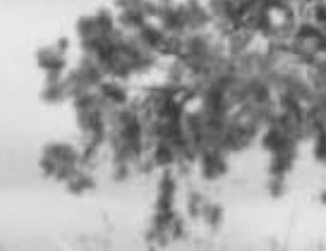

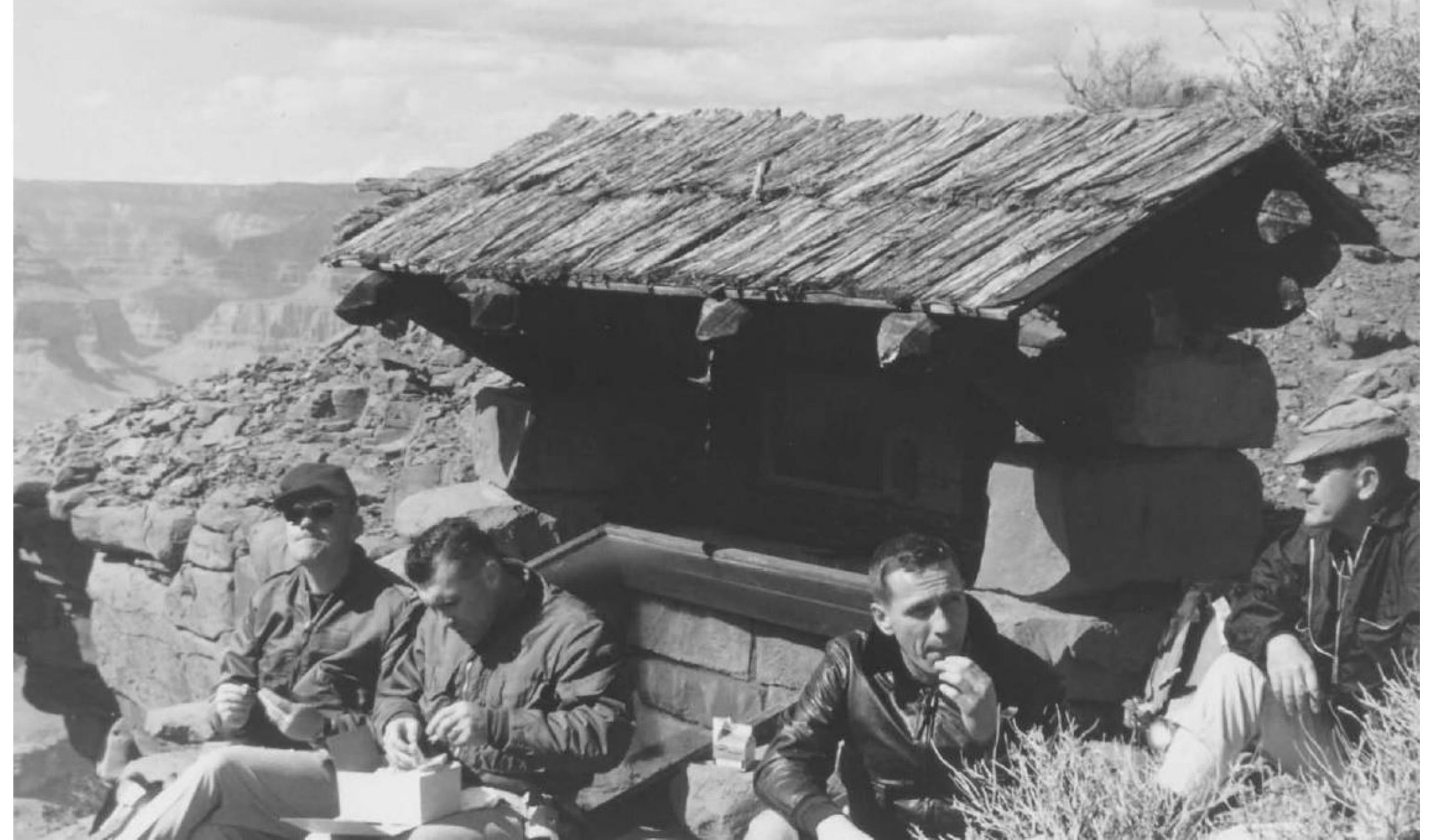


4.

\section{Aly X}

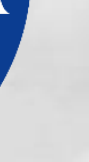

\section{-itiger} . से

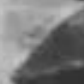 \\ I $\quad 30 \%$}

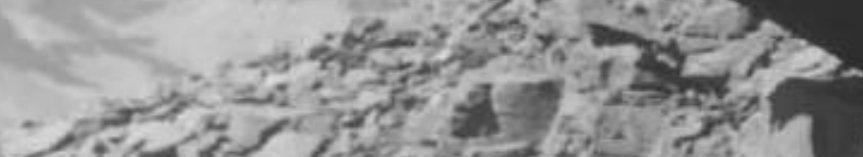
$6=0$, $3=43$

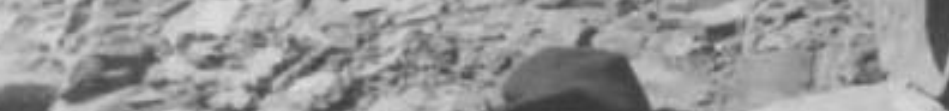

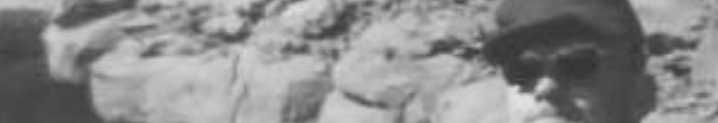

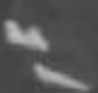

$=-2$
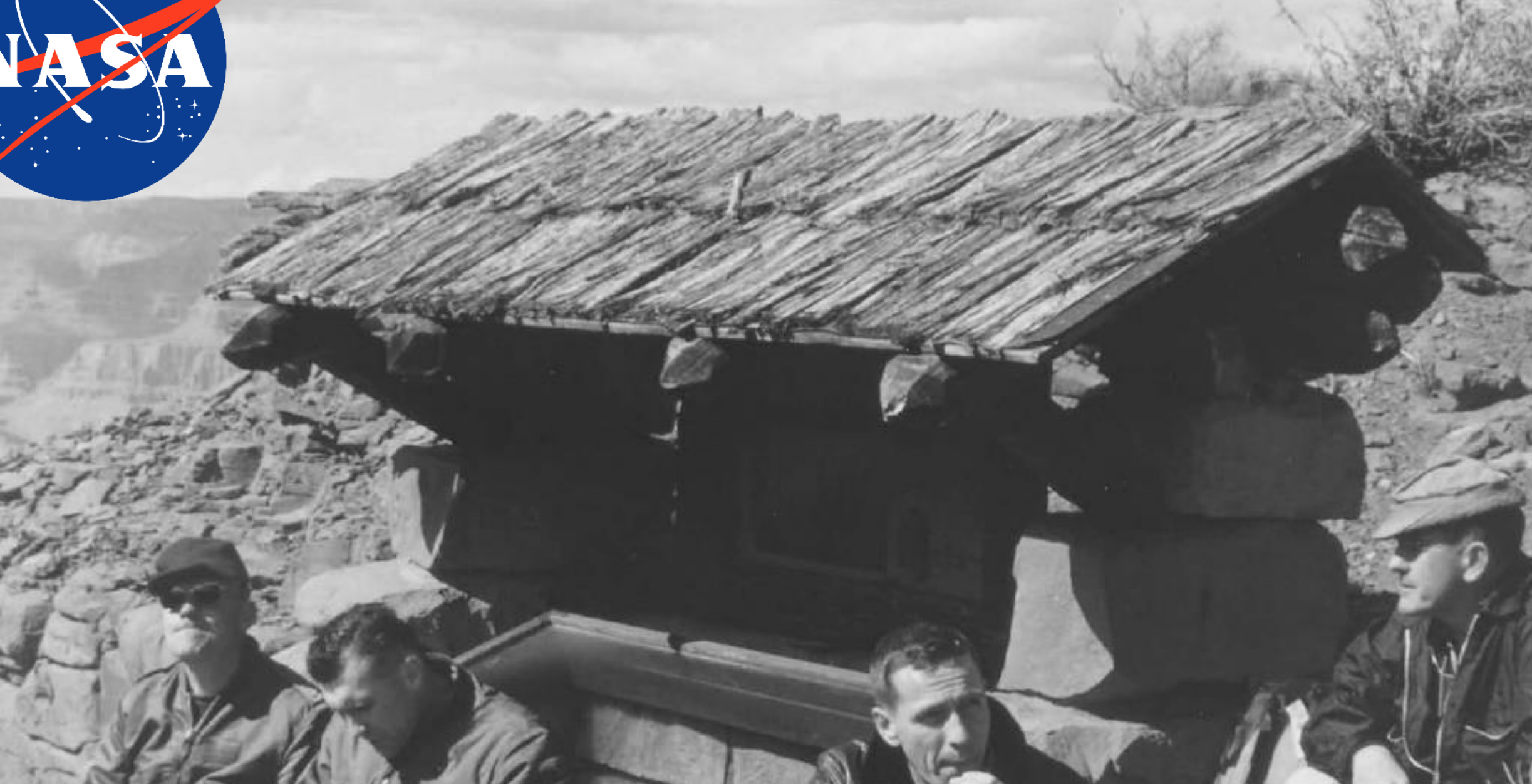

-

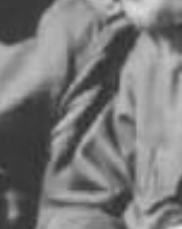

- -1 ma

\section{by - S m} $=98-1-2$

\section{2}




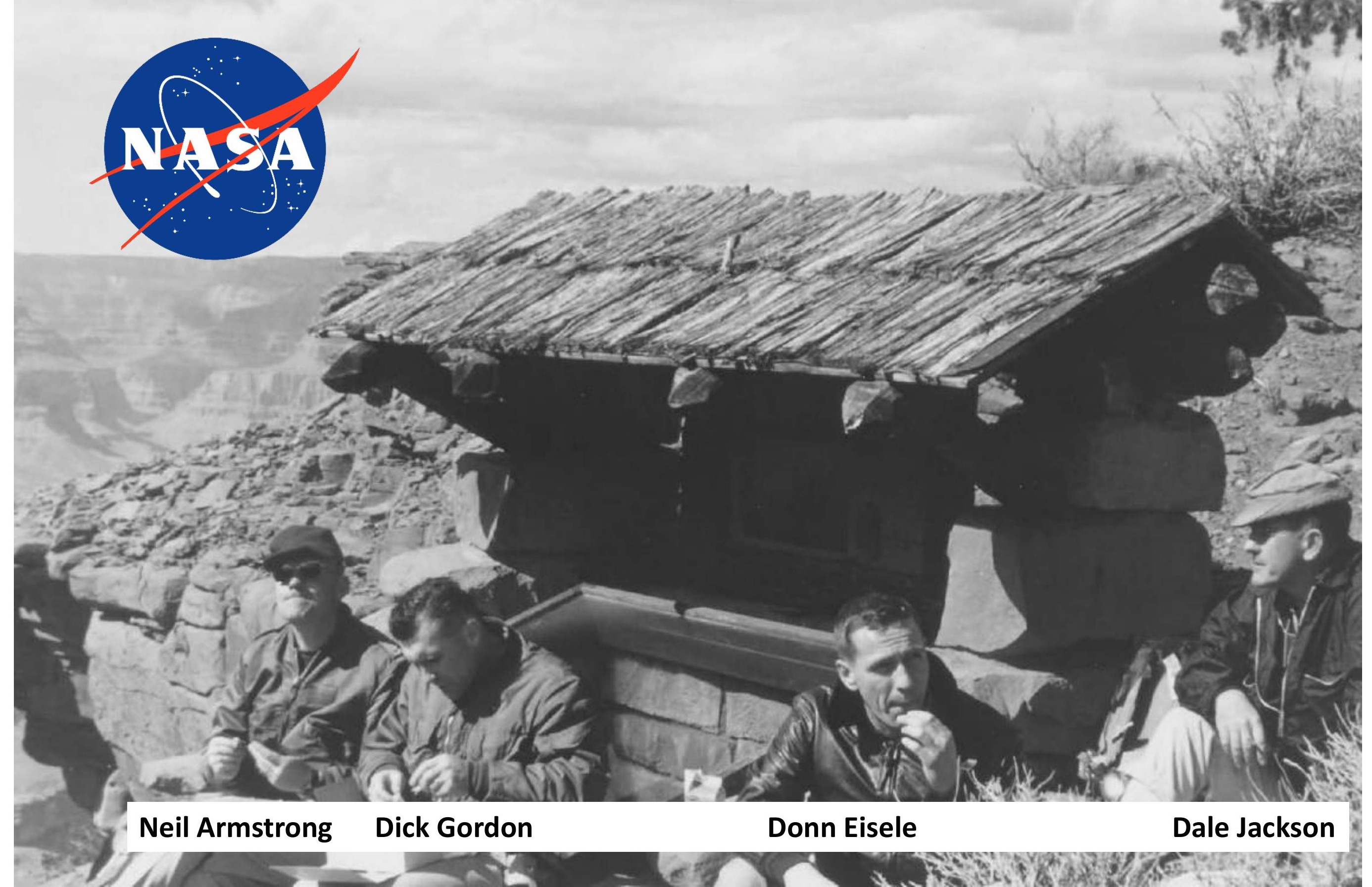




\section{Fossil Fern Exhibit (2008)}

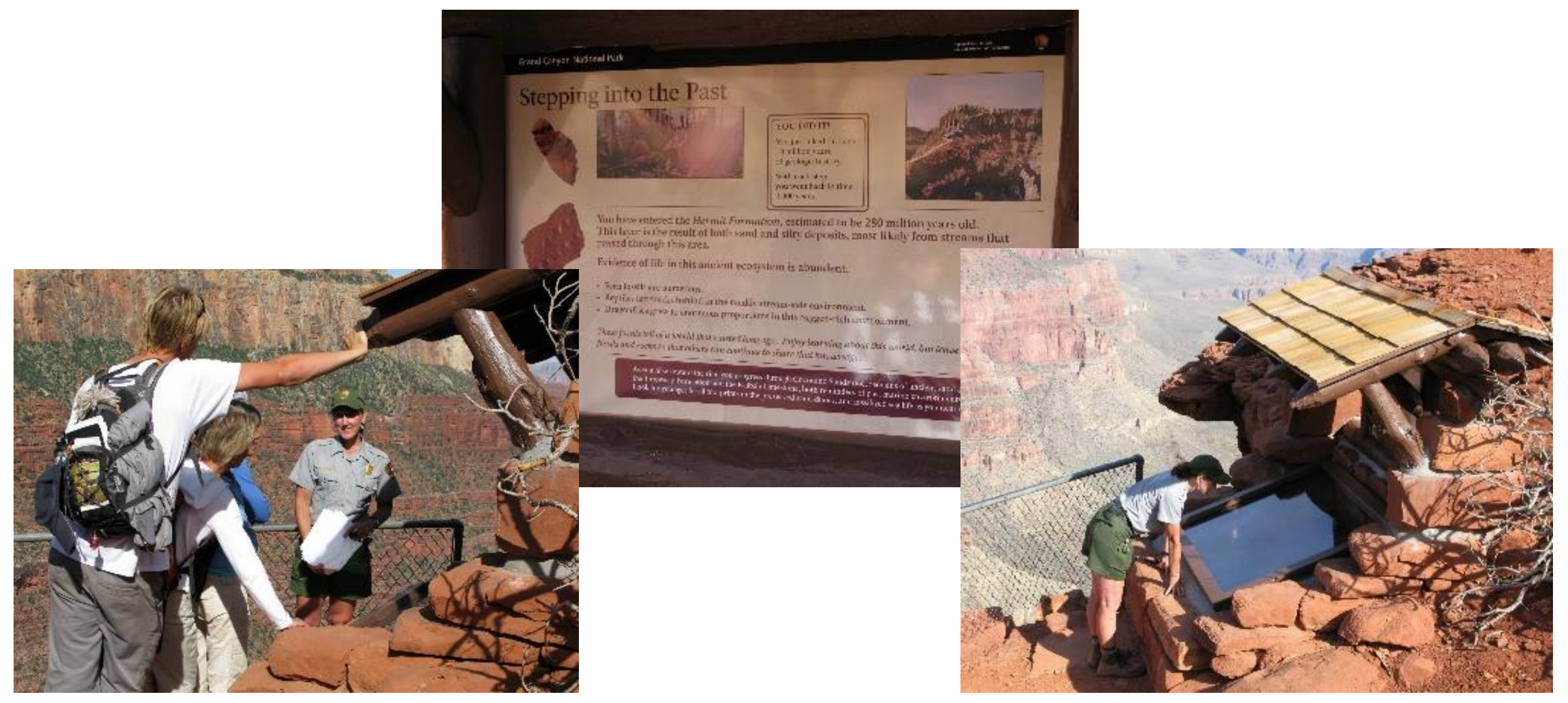




\section{Paleontology Interpretation}

- Fossil Fern Exhibit

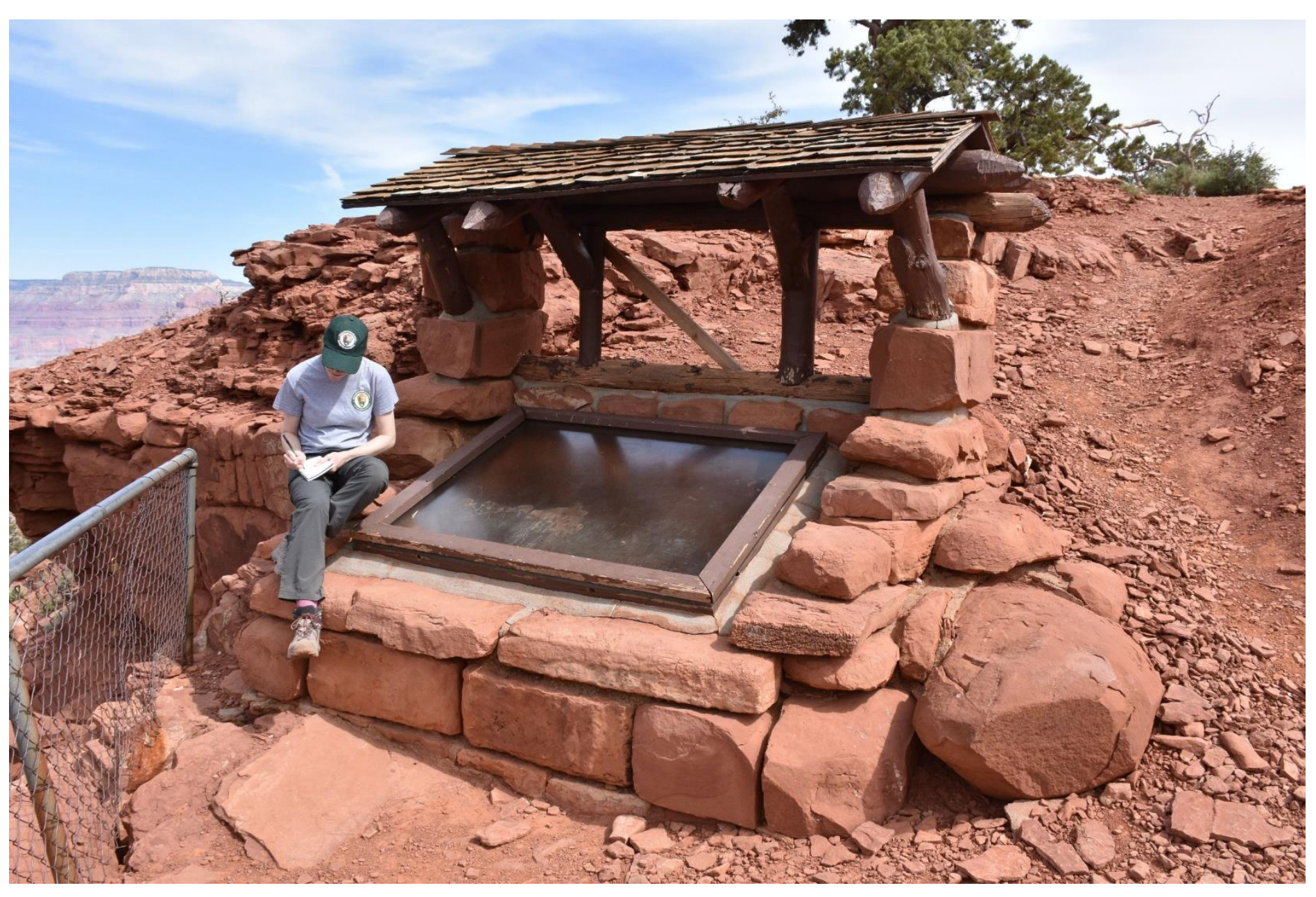




\section{Paleontology Interpretation}

- Ranger Programs

- Curriculum Based

- Distance Learning

- Classroom Ranger Visits

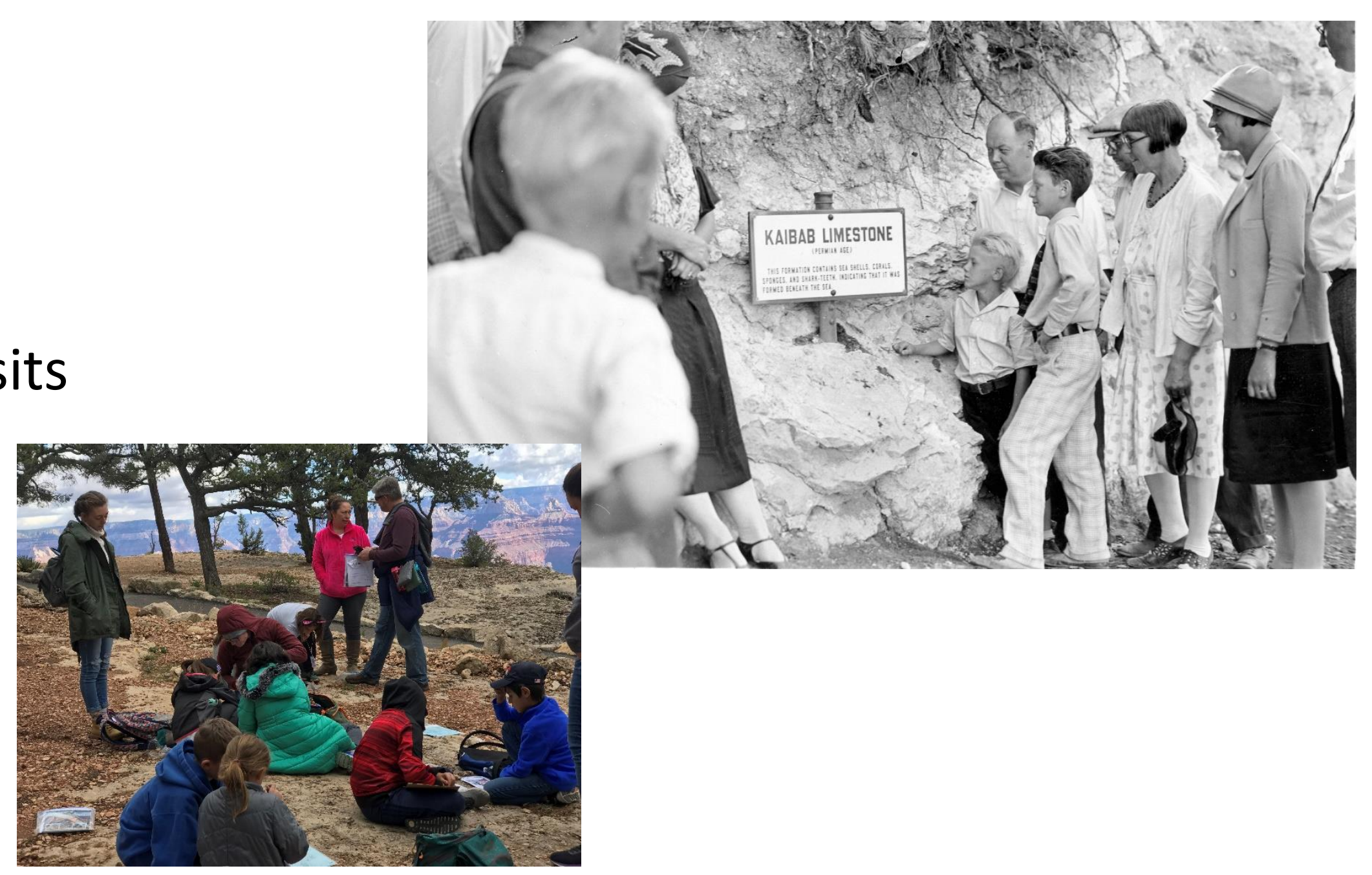




\section{Paleontology Interpretation}

- National Fossil Day Event

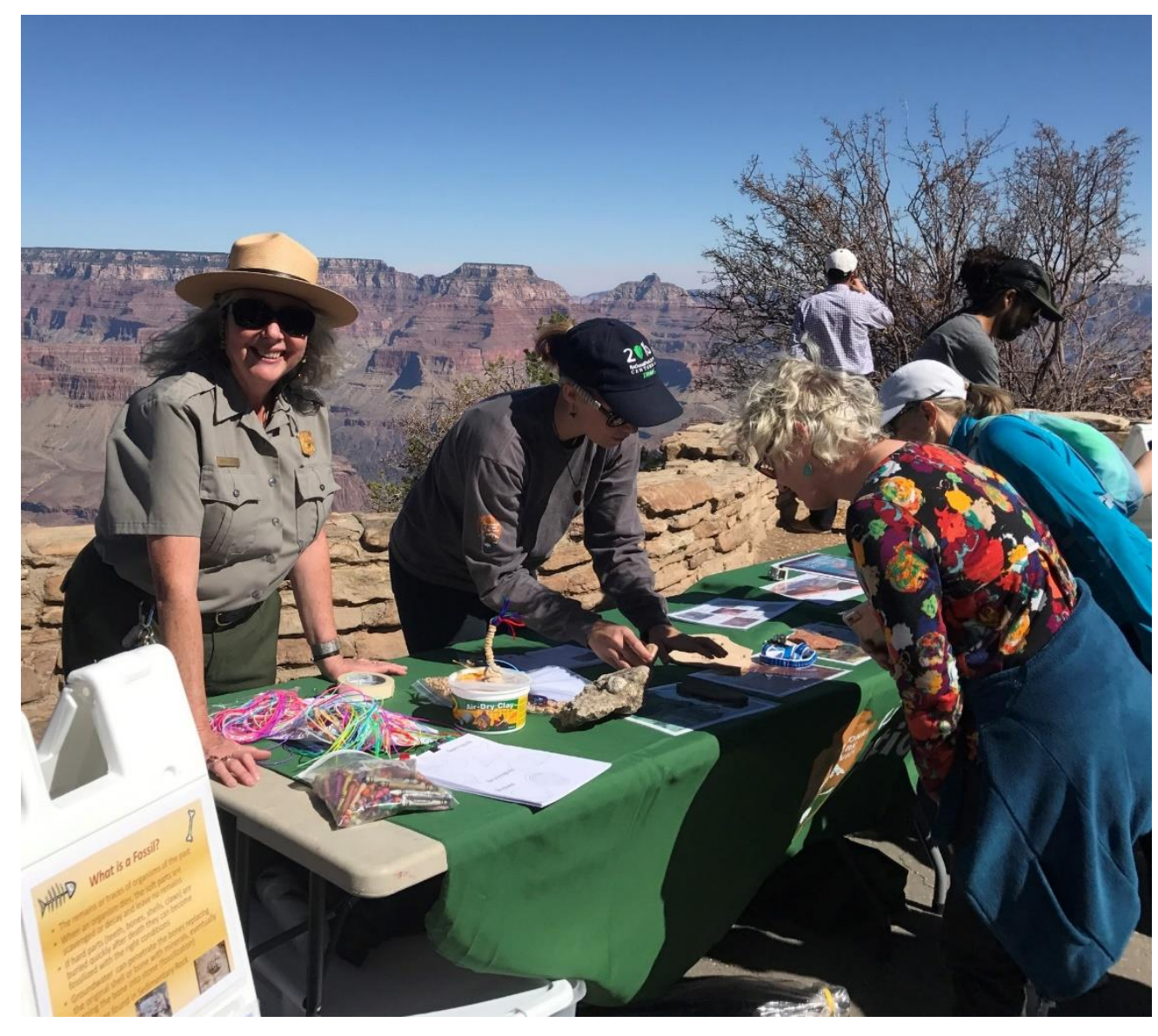

NATIONAL
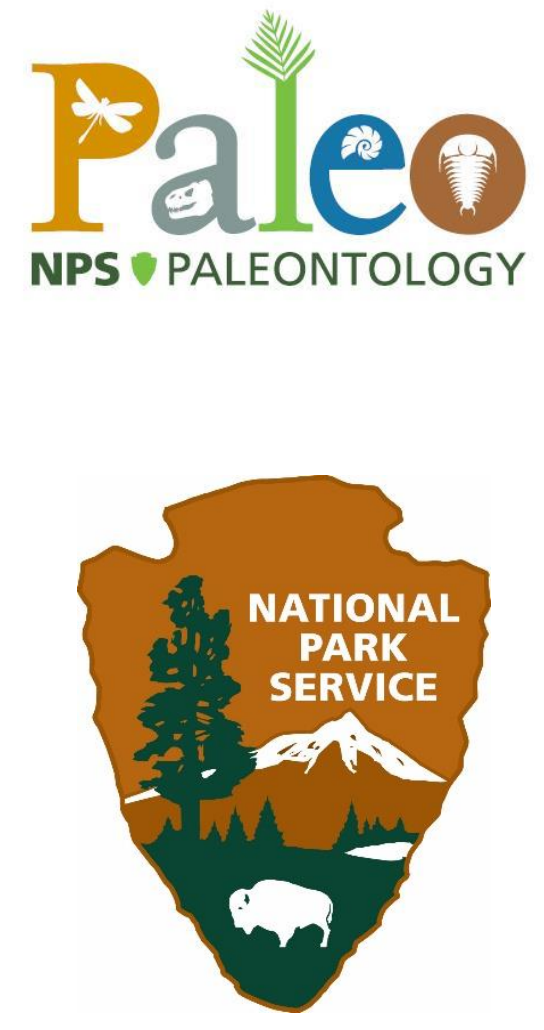
FOSSIL DAY

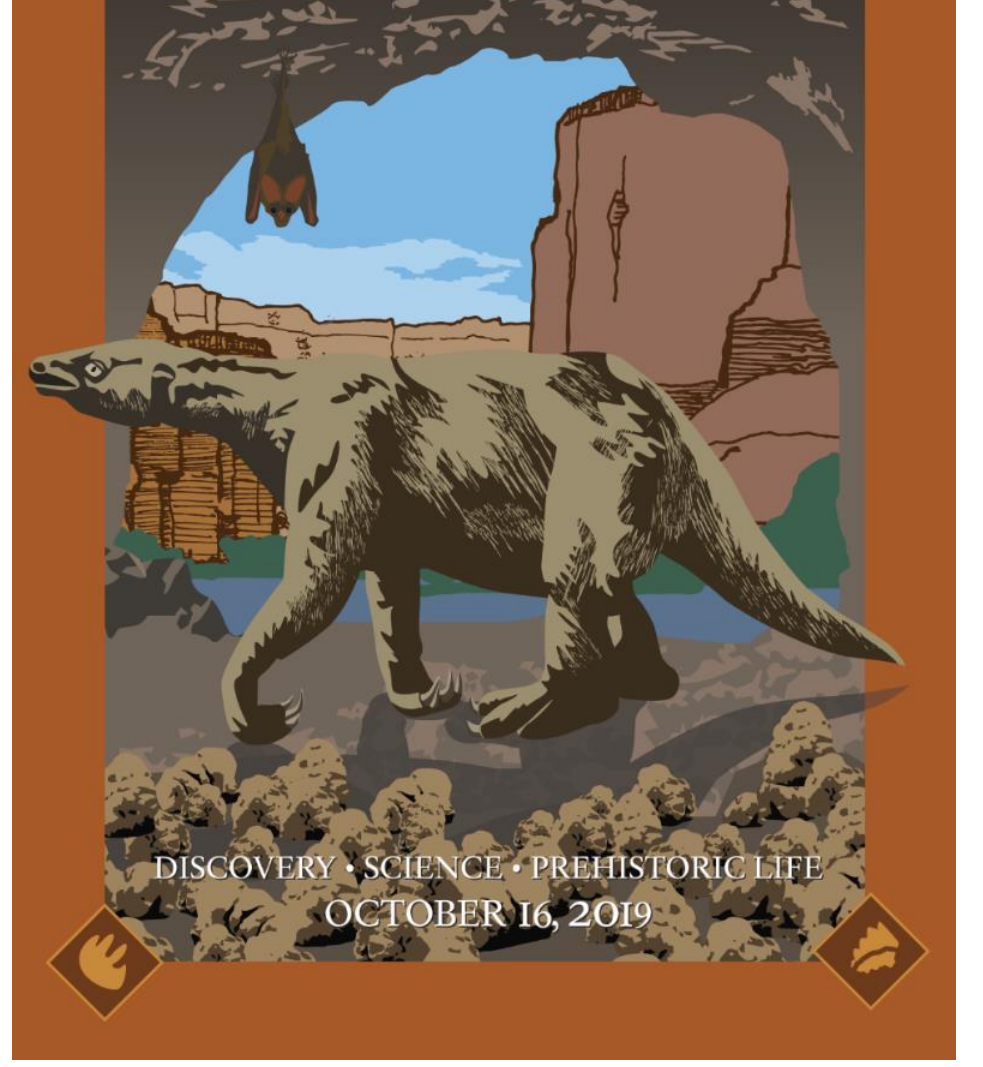




\section{Paleontology Interpretation}

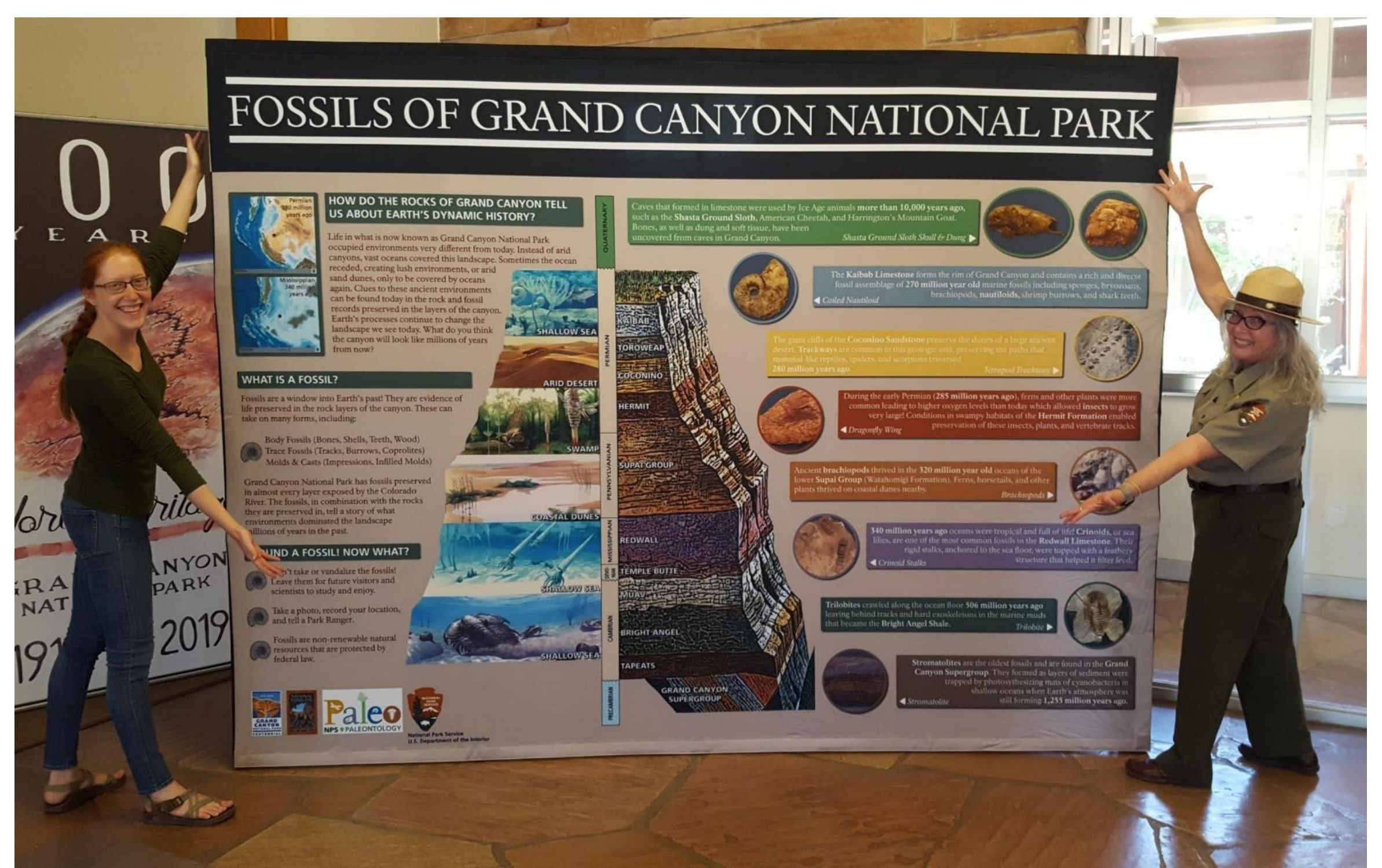




\section{Paleontology Interpretation}
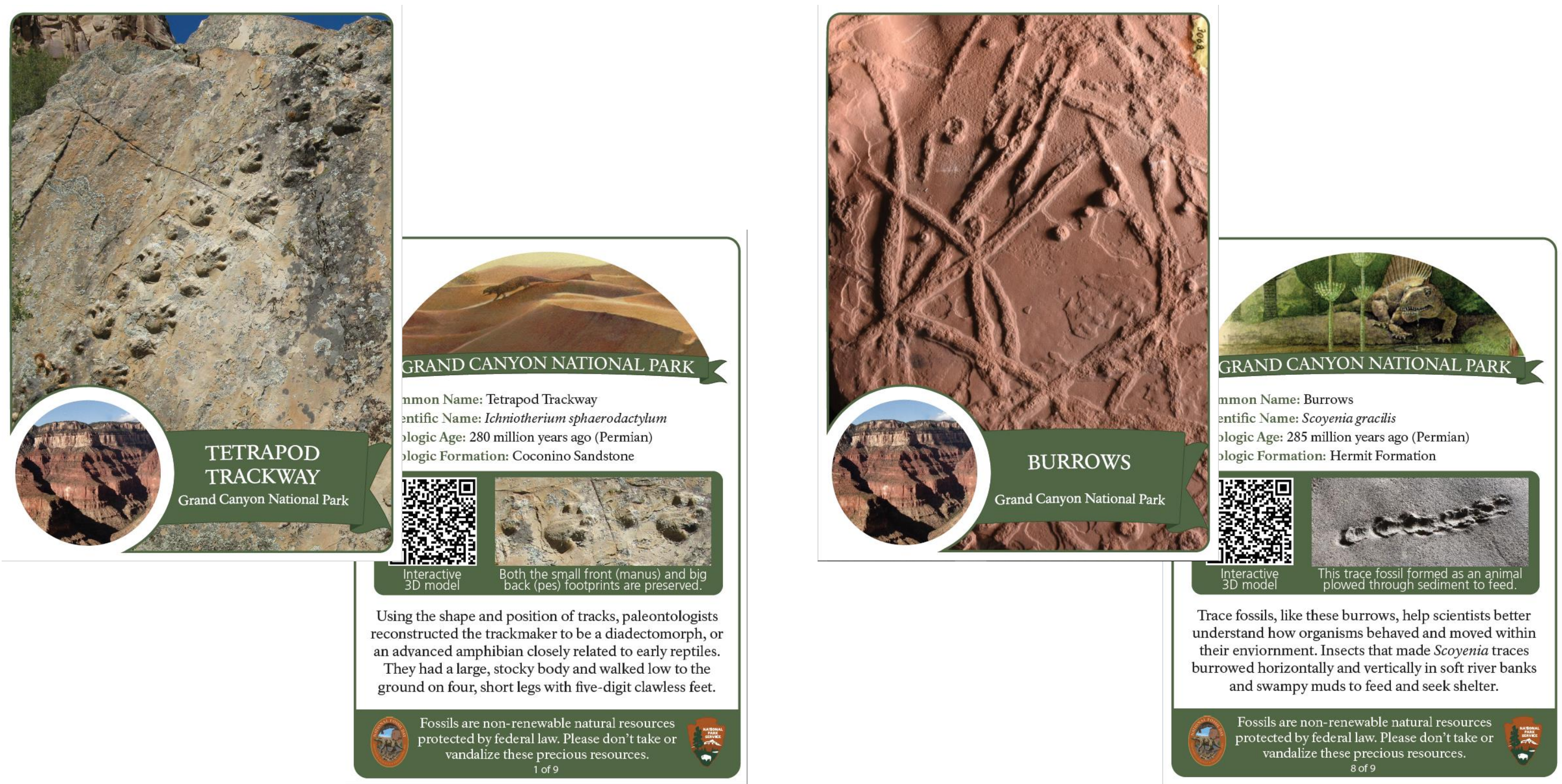


\section{Paleontology Interpretation}

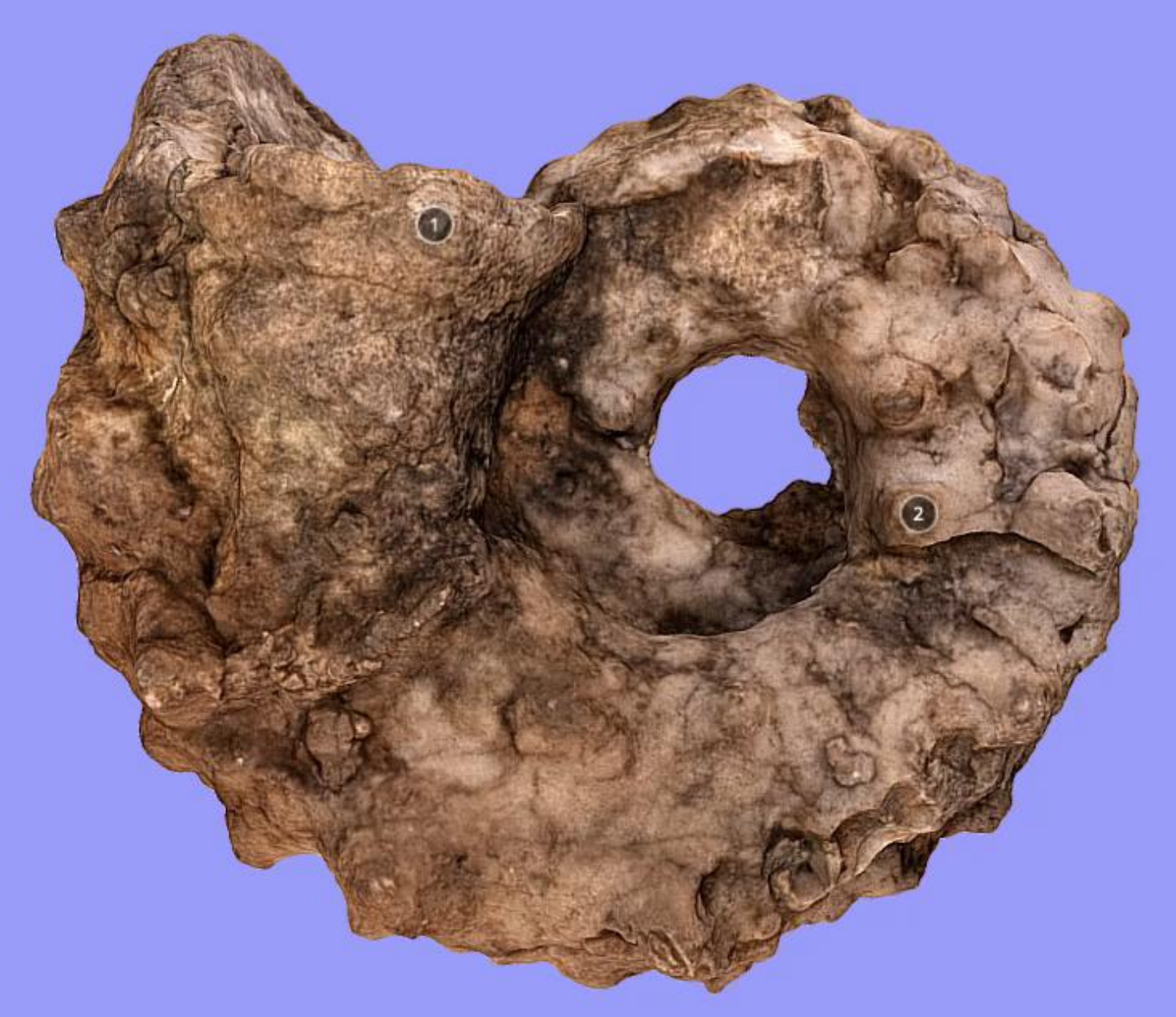




\section{Future Plans}

- Monitoring

- More Surveys

- Encouraging Youth - Future Fossil Stewards

- Dedicated NPS Staff 
4. Never doubt that a small group of thoughtful, The committed cityens can change the world; lindeed,

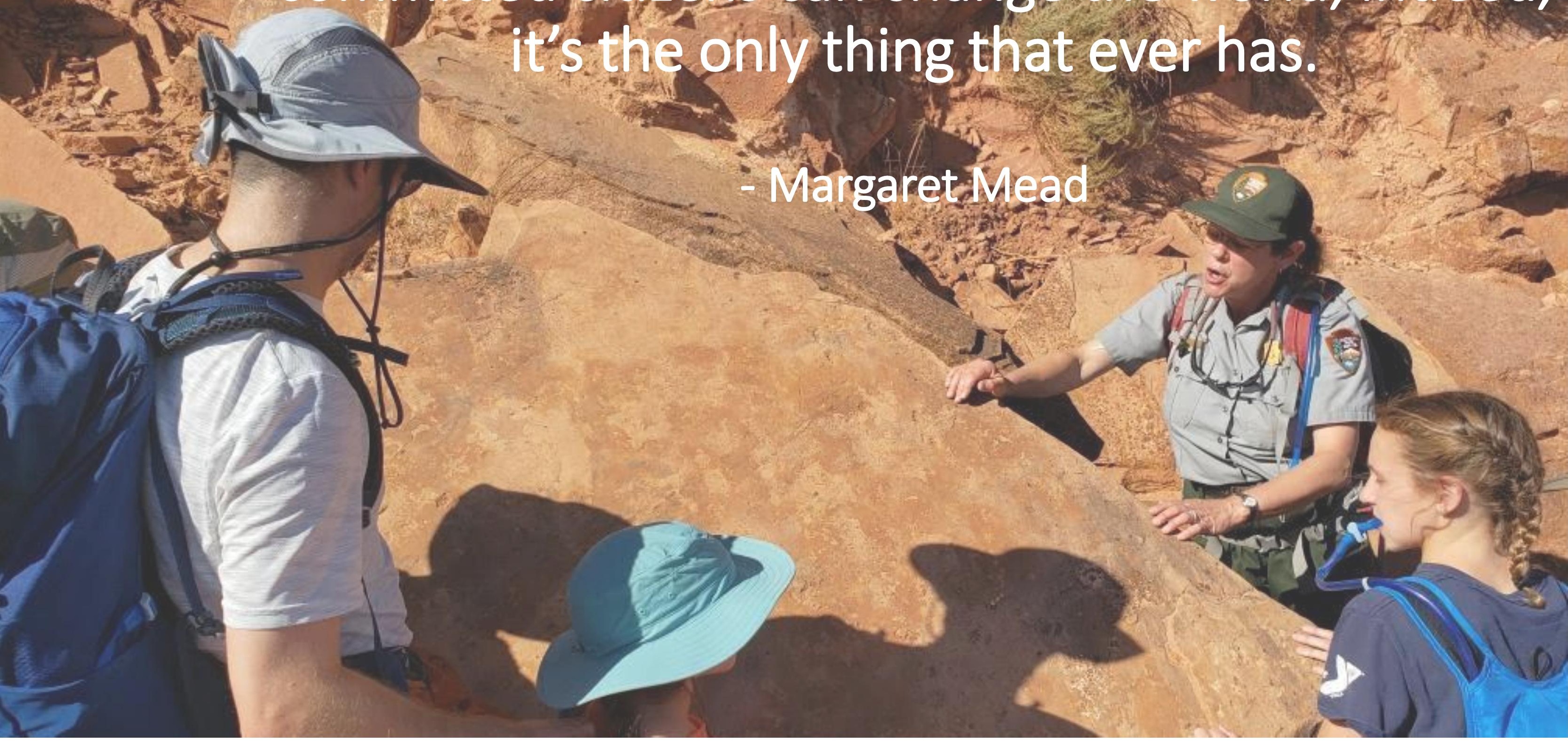




\section{Special Thanks}

Grand Canyon National Park

Geological Society of America Grand Canyon Conservancy

Conservation Legacy

Environmental Stewards

Americorps

American Conservation Experience
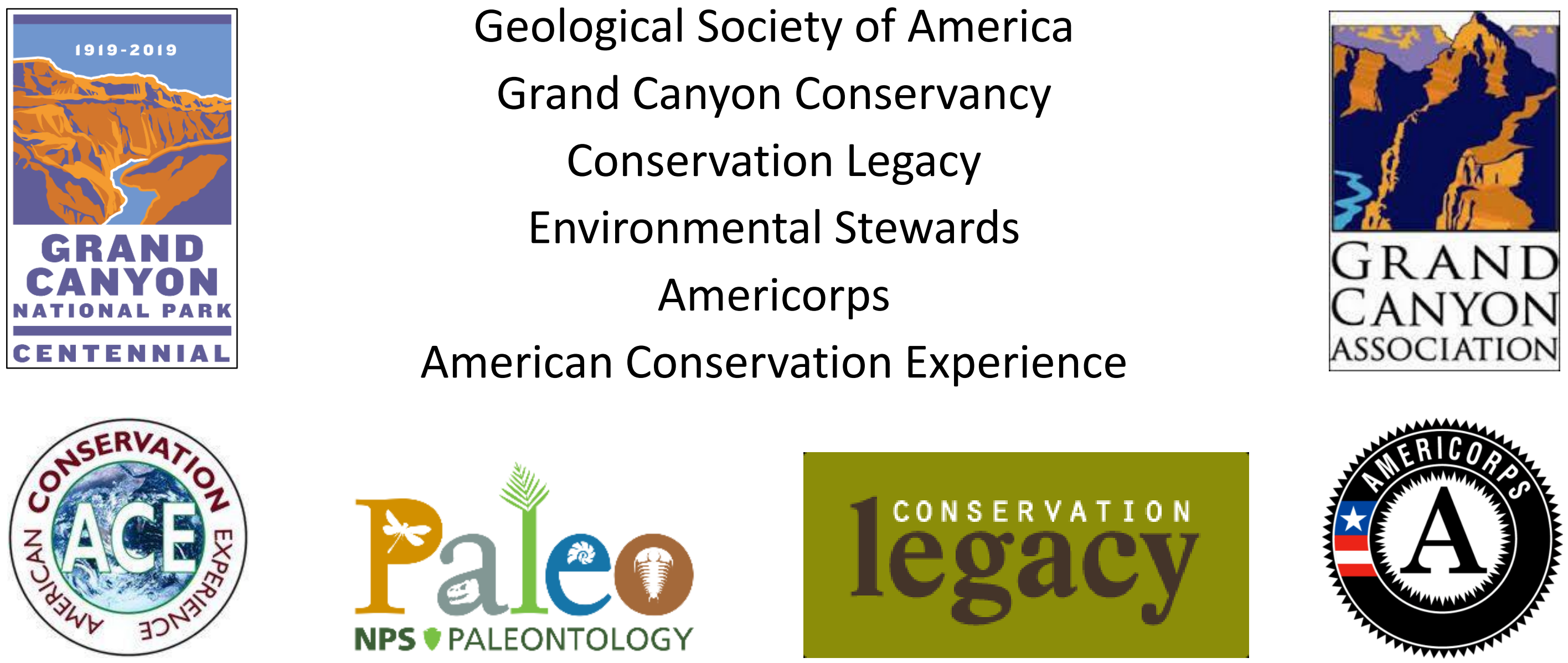


$$
x^{2}+\infty
$$

$$
8
$$

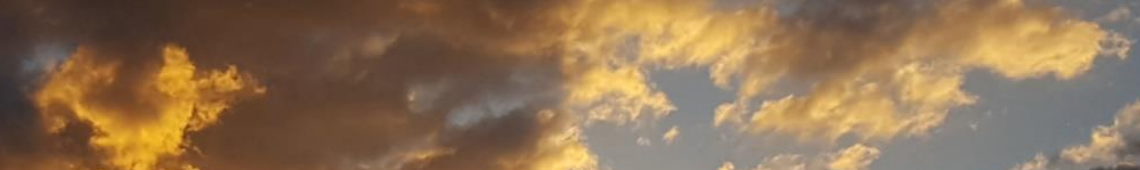

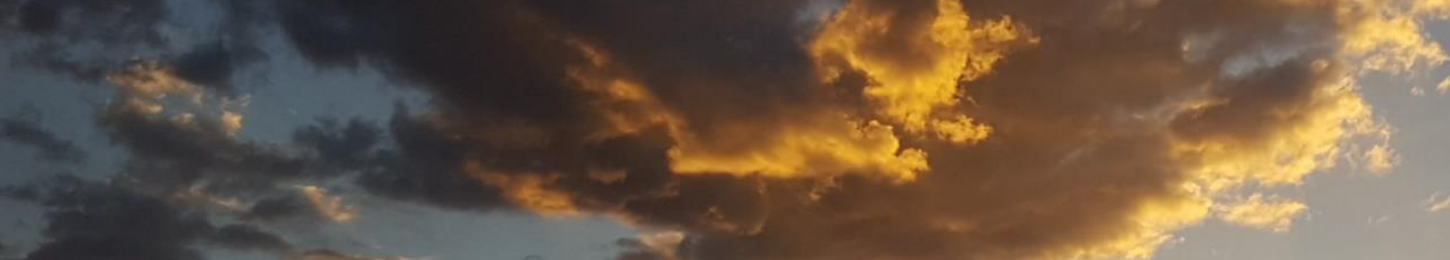

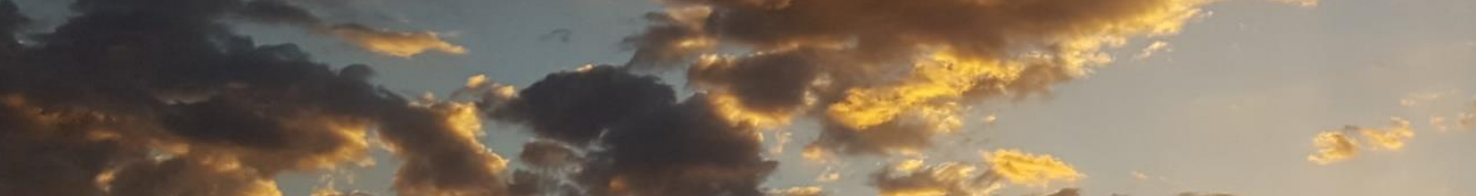

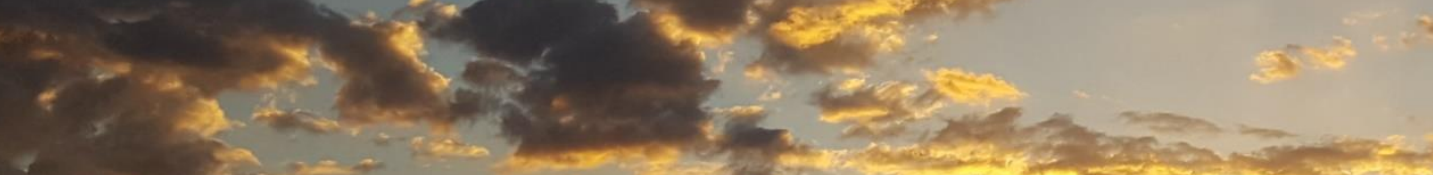

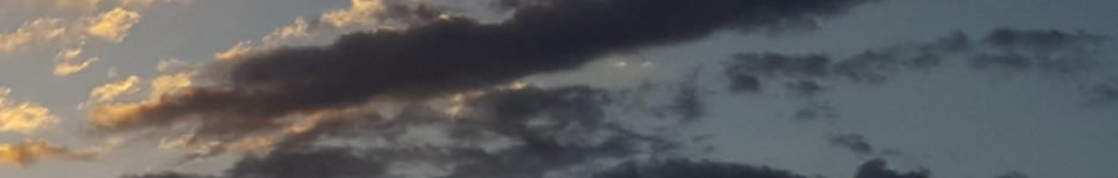

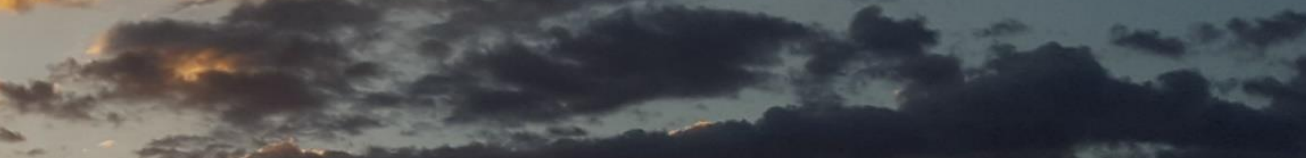
$-x-200-10$ $x^{3}+x^{2}$ 3

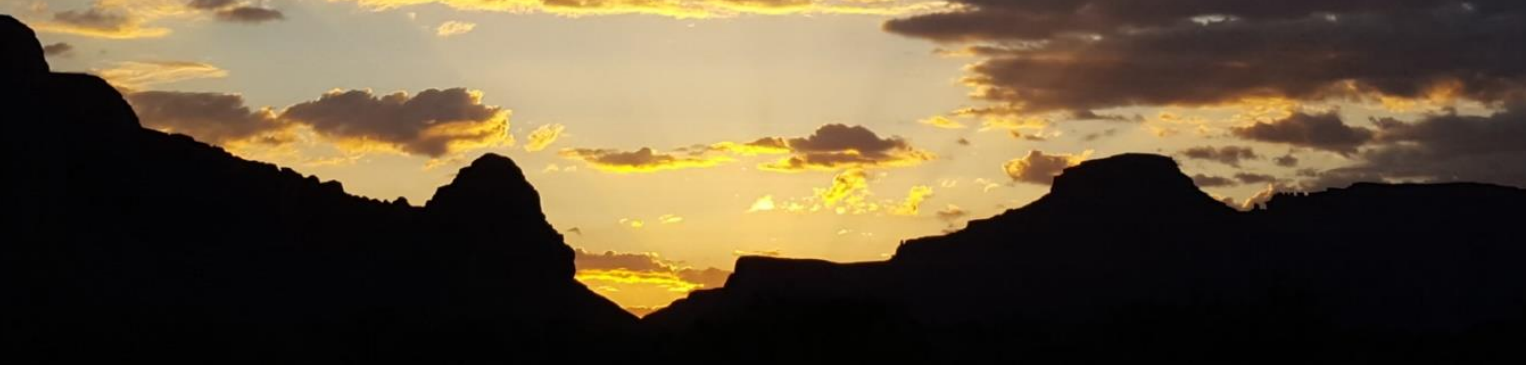

$\frac{4}{4} \quad x$ $-2$

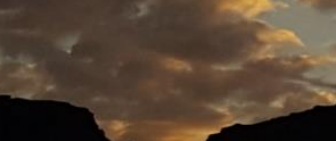

